University of Wollongong

Research Online

Faculty of Social Sciences - Papers (Archive) Faculty of Arts, Social Sciences \& Humanities

2016

Garden-related environmental behavior and weed management: An Australian case study

Ren $\mathrm{Hu}$

University of Wollongong, rh407@uowmail.edu.au

Nicholas J. Gill

University of Wollongong, ngill@uow.edu.au

Follow this and additional works at: https://ro.uow.edu.au/sspapers

Part of the Education Commons, and the Social and Behavioral Sciences Commons

Research Online is the open access institutional repository for the University of Wollongong. For further information contact the UOW Library: research-pubs@uow.edu.au 


\title{
Garden-related environmental behavior and weed management: An Australian case study
}

\begin{abstract}
This study aims to identify the key drivers of two garden-related environmental behaviors (GEBs): plant choice and bush-friendly behavior. This is important for biodiversity conservation threatened by weed invasion from domestic gardens. The effects of self-control, time pressure, and knowledge of weedcontrol initiatives were examined. A mail survey was sent to suburban residents living adjacent to native bushland in Wollongong, New South Wales. Regression analysis and structural equation modeling (SEM) were used. The path models for SEM were based on the theory of reasoned action. The results indicate that attitude, perceived harm, and knowledge of weed-control initiatives exert an effect on GEBs through intention; self-control influences intention to increase native garden plants; and time pressure influences bush-friendly behavior. The results emphasize the importance of searching for predictors that are specifically related to the examined behavior instead of only relying on a universal model to explain behavior. Behavior-intervention strategies for weed management are derived.
\end{abstract}

\section{Keywords}

behavior, study, environmental, case, related, garden, australian, management, weed

\section{Disciplines}

Education | Social and Behavioral Sciences

\section{Publication Details}

Hu, R. \& Gill, N. (2016). Garden-related environmental behavior and weed management: An Australian case study. Society and Natural Resources, 29 (2), 148-165. 


\section{Garden-related environmental behavior and weed management: an Australian case}

study

This study aims to identify the key drivers of two garden-related environmental behaviors (GEBs: plant choice and bush-friendly behavior). This is important for biodiversity conservation threatened by weed invasion from domestic gardens. The effect of self-control, time pressure and knowledge of weed-control initiatives were examined. A mail survey was sent to suburban residents living adjacent to native bushland in Wollongong, New South Wales. Regression analysis and structural equation modeling (SEM) were used. The path models for SEM were based on the theory of reasoned action. The results indicate: attitude, perceived harm and knowledge of weed-control initiatives exert an effect on GEBs through intention; self-control influences intention to increase native garden plants; time pressure influences bush-friendly behavior. It emphasizes the importance of searching for predictors that are specifically related to the examined behavior instead of only relying on a universal model to explain behavior. Behavior-intervention strategies for weed management are derived.

Keywords: garden-related environmental behavior; self-control; theory of reasoned action; time pressure; weed management; weed-control initiatives 


\section{Introduction}

Since European settlement, about 27,000 known plant species have been introduced to Australia (Groves et al. 2005). Exotic plants have become one of the foremost threats to native biodiversity considering that significant endemicity renders Australian ecosystems more vulnerable to biological invasion (Blood and Slattery 1996). While ecological change due to invasive plants is inevitable (Hobbs et al. 2006), biological invasion in urban settlements and elsewhere remains an agent of change in Australian ecosystems that is generally viewed as undesirable (Moss and Walmsley 2005). Garden plants have been, and remain, a significant source of invasive plants. About $66 \%$ of the naturalized exotic plant species in Australia originated in nurseries or domestic gardens (Groves et al. 2005). An example of such plants is Lantana camara which threatens numerous native and threatened species in Australia, including in our study area (Turner and Downey 2010). Retail nurseries, changing garden fashions, and demand from gardeners particularly contribute to plant importation (Moss and Walmsley 2005). Nurseries, as dominant garden plant providers, always search for exotic plants to create or follow fashions (Groves et al. 2005). It is important to understand the factors that influence gardeners' preference towards native or non-native plants, and formulate behavior intervention strategies.

The abundance of exotic plants is higher in urban settlements than in agricultural or reserved areas because of enhanced transport capacities (Sullivan et al. 2005). Many Australians have understandings of urban nature that diverge from those of conservation professionals (Davison and Ridder 2006), or do not recognize invasive garden plants as a problem (Head and Muir 2004). Some urban natural areas can support high native 
biodiversity, but their long-term persistence is threatened by urban development and associated processes including garden plants escaping (Garden et al. 2010). Where remnants of ecologically valuable vegetation remain in cities and adjoin gardens, gardening and relevant practices (e.g. weeding and even restoring nearby bushland) of residents are significant for biodiversity conservation (Miller and Hobbs 2002).

Gardening is one of the most popular outdoor activities in Australia, and is familiar to most urbanites. But the negative environmental impacts of garden-related activities are often overlooked by gardeners. The comprehensive purchasing plants for beauty or garden style provides an impetus for importing ornamental plants (Head and Muir 2004). After being grown in gardens, these plants can further spread through, for example, garden waste dumping by gardeners.

To explain garden-related behaviors, previous studies examined various socio-demographic and psychological predictors, such as attitude (Zagorski et al. 2004) and environmental identity (Kiesling and Manning 2010). Compared to other environmental behaviors, for example recycling, garden-related environmental behaviors (GEBs) that minimize the possibility of weed escaping are not widely studied. We examined suburban residents’ plant choices (choosing native garden plants) and bush-friendly behavior (weeding and bush restoration in neighboring reserves) as two GEBs, and their relationship with certain variables. The two behaviors were selected, because they reflect aspects of gardening's contribution to restricting the spread of non-native plants, and to prevention of weeds escaping. 


\section{Behavior theory}

To gain more understanding of environmental behavior, we draw on the theory of planned behavior (TPB) (Ajzen 1991), and the theory of reasoned action (TRA) (Fishbein and Ajzen 1975). The TPB is an extension of the TRA with the addition of a new concept, perceived behavioral control (PBC). These theories assume that individuals' feelings and thoughts towards the environment partly shape their environmental behavior (Oreg and Katz-Gerro 2006).

In the TPB, behavior's direct predictor is intention (how much effort people decide to make to perform certain behavior). When people decide to act, they also need opportunities and resources, reflected as PBC, representing people’s actual control over a behavior. If one individual will perform an easy behavior or has substantial volitional control over the behavior, the TRA (a simplified version of the TPB) should be sufficient to predict behavior (Payne et al. 2004). It should be increasingly difficult for the TRA to predict behaviors over which volitional control decreases, and PBC would be increasingly necessary to be included in the model. Further, intention is influenced by two other factors: attitude ("favorable or unfavorable evaluation or appraisal of the behavior") and subjective norms ("perceived social pressure to perform or not to perform the behavior”) (Ajzen 1991, p.188).

The predictive power of the TPB/TRA has been examined by Sutton (1998) who summarized 9 meta-analyses and quantitative reviews of the TPB/TRA, and reported the variance explained in intention and behavior respectively ranged from 40\% to 50\%, and 19\% to $38 \%$. The TPB/TRA has been applied to various behaviors relevant to plant choice (consumer behavior) and bush-friendly behavior (physical outdoor activity), for example 
gardening, green consumption, home-based environmental behaviors, physical activity and conservation behavior (Collette et al. 1994; Lautenschlager and Smith 2007; Barr 2008). The TPB/TRA variable attitude has been found to be related to the species composition of gardens (native or non-native) (Zagorski et al. 2004). As such, we decided to test the TRA with additional predictors against GEBs. We also measured respondents’ perceived harm of non-native plants as a predictor of intentions to increase planting native plants or remove non-native plants from neighboring reserves (intention to increase and intention to remove respectively served as an explanatory variable of plant choice and bush-friendly behavior). Perceived harm reflects specific environmental concern (Oreg and Katz-Gerro 2006), which is part of environmental attitude and reported to be significantly related to environmental behavior (Mobley et al. 2010). Attitude, subjective norm and perceived harm were hypothesized to indirectly influence GEBs through intention. PBC was not involved, because gardens and the surrounding environment are largely under control by gardeners (Power 2005), reflecting their volitional control on GEBs.

Despite the success of the TPB/TRA, its short-comings have also been reported, and revisions by including variables to enhance its predictive power are proposed. Sutton (1998) also suggested the TPB/TRA did not always function well in predicting intention and behavior. Chao (2012) reported, among the TPB constructs, subjective norms might fail to significantly influence intention. Another issue is the widely reported disparity between public environmental awareness and behavioral response, explained as “value-action gap” or “intention-behavior gap” (Lorenzoni et al. 2007; Barr 2008). Blood and Slattery (1996) 
reported even if people had concern about weeds and realized that some garden plants are harmful weeds, some of them still felt reluctant to remove these plants from their garden.

In the following, I present two concepts (self-control and time pressure) that may not be accounted for by the TPB/TRA, and explore potential predictors for GEBs.

\section{Self-control}

A possible course of action for individuals is that they may make a plan to guide action, but are then diverted from that plan because of being tempted by other choices. Ditto et al. (2006) reported that people frequently go against their self-interest, which they almost immediately regret. These phenomena are hard to explain with the TPB/TRA (Verplanken and Sato 2011), as these theories are based on a rational model in which people act on the basis of information regarding consequences (Lorenzoni et al. 2007). Impulsive behaviors can be attributed to visceral factors, including desires and emotions (Loewenstein 1996), which are characterized by “a direct hedonic impact”, and influence the desirability of certain actions (Loewenstein 1996, p.272). They can be evoked by the proximity to desired objects (Vohs and Faber 2007) and “lead people to be disproportionately influenced by the anticipated rewards of immediate gratification” (Ditto et al. 2006, p.99).

Loewenstein and O’Donoghue (2004) suggested that the impulsive nature of human psychology should be introduced into traditional behavioral paradigms which mainly emphasize reason-based action. One way to do this is to introduce a measurable construct, such as self-control that reflects people's capacity to over-ride visceral factors (Tangney et al. 2004). The role of self-control in influencing behavior could be similar to perceived 
behavioral control (PBC) in the TPB. However, while impulse buying is difficult to account for using the TPB (Verplanken and Sato 2011), self-reported self-control is able to predict resistance to impulse buying (Vohs and Faber 2007). PBC mainly focuses on the perception of external conditions, such as resources and opportunities. Response to PBC questions in surveys is based on factors that are realistic or readily estimated (Ajzen 1991). As for self-control, it represents people's control over internal impulsivity, and is more relevant when facing the conflict between immediate gratification and long-range goals.

Self-control is also important for addressing environmental issues (Thøgersen 2005). Like other buying behavior, purchase of garden plants is subject to impulse buying (HRDC 1991; Tzavaras et al. 2010) caused by self-control failure (Verplanken and Sato 2011). Even if some gardeners have concern about weeds, they would still buy invasive plants for their attractive appearance serving as a sensory signal amplifying the purchase desire (Vohs and Faber 2007). Thus, we hypothesized that self-control influenced intention to increase planting native plants, considering when people intend to buy certain plants or resist buying certain plants, they would consider their self-control strength (Loewenstein 1996).

\section{Time pressure}

Time pressure has been reported to be a constraint for pro-environmental behavior and a contributor to “environmental values/behavior gap” (Kennedy et al. 2009). It is usually caused by heavy workloads in paid work and home duties, and related to perception of fatigue. The phenomenon of "too much to do and not enough time" has been recognized as universal in developed countries (Gunthorpe and Lyons 2004, p.201), whereby long working 
hours are structurally embedded in economic systems. However, absorption of environmental knowledge, and implementation of pro-environmental behavior usually need extra inputs of time and energy (Prillwitz and Barr 2011). For GEBs, gardeners spend extra time checking the invasiveness of plants from retailers and removing invasive plants from their garden.

Another dimension of time pressure is priority, which blurs the relationship of time pressure with perceived behavioral control. Even if a person has enough time and ability to perform certain behavior, he/she may not do it because time is spent on other activities with higher priority, or on less time-consuming alternatives. Environmentally detrimental choices are renowned for convenience and low cost, and are often preferentially chosen, especially when time is limited. Hjorthol (2001) reported that time pressure was a frequent reason for traveling by car rather than more sustainable means of transportation. Lassen (2010) argued that traveling by airplane was usually the first choice when people are going to travel internationally partly because of time efficiency. Bush-friendly behavior and sustainable travel behavior are similar in the way that they both need extra time input, and time pressure also impedes the performance of gardening activity (Dignam et al. 2003).We therefore hypothesized that time pressure moderated the relationship between bush-friendly behavior and intention to remove non-native plants from neighboring reserves on the assumption that time pressure contributes to "intention-behavior gap".

\section{Other variables}

Within the circumstance of our study area, the Wollongong Local Government Area (LGA), there are other factors that influence people’s GEBs. City council and the nursery industry 
community have conducted weed-control initiatives, distributing guides on choosing plants through webpage, plant retailers, gardening clubs and educational institutes, and organizing regular workshops and outdoor activities on weed removal for residents. These initiatives provide local residents with knowledge, skills and opportunities to join weed management. Gardeners’ level of knowledge about the initiatives reflects what they know about weeds and whether they have used or joined the initiatives. Thøgersen (2005) maintained that knowledge about environmental issues, how they relate to behavior, and what can be done to mitigate the impacts of behavior are necessary for people to adopt pro-environmental behavior. With insufficient or abundant contradictory information people tend not to perform pro-environmental behavior (Kennedy et al. 2009). Moreover, environmental literature (e.g. magazines or brochures), engagement, and outdoor experience, which can be provided by the initiatives, have been found to influence environmental behavior (Mobley et al. 2010). Thus, knowledge of initiatives was hypothesized to explain all examined intentions and GEBs in this study.

Additionally, residents' type of boundary between garden and bushland, and their most important source of garden plants were also involved in the analysis (some common socio-demographic variables, such as gender, were also tested, but found insignificant). These background factors represent obstacles or opportunities to engage in certain behavior (Mobley et al. 2010). A solid wall between a garden and outside environment can preclude cross-boundary activities, and reflect this gardener's low interest in bushland conservation (Head and Muir 2006). Gardeners who often visit commercial plant retailers have more chance to see aesthetic non-native plants being promoted (Moss and Walmsley 2005), but the 
relationship between which plant retailers are most visited and resultant plant purchases have not been studied. Thus, plant source and garden boundary were hypothesized to influence plant choice and bush-friendly behavior respectively.

The literature review introduces the weed issues in Australia and emphasizes gardeners' behavior. Among the variables described above, this study aims to identify the key factors that influence the GEBs (plant choice and bush-friendly behavior). To complement existing research, we investigated self-control, time pressure and knowledge of initiatives in relation to GEBs. Path analysis and regression analysis were applied to test the hypotheses described above.

\section{Methods}

From August to September 2013, a self-administered mail survey was delivered to Wollongong (NSW, Australia) households located adjacent to native vegetation designated as “Natural Areas” by Wollongong City Council under the NSW Local Government Act 1993.

The Wollongong LGA, located in the ecologically significant Sydney Basin Bioregion, has rugged terrain intertwining native vegetation with urban settlements, and is appropriate for studying residents’ conservation behavior towards bushland (Head \& Muir 2006). Weed-control initiatives conducted here include Greenplan, Grow Me Instead, Grow Local, and Bushcare. Greenplan provides Wollongong ratepayers with affordable local plants at monthly sales at council’s Botanic Gardens nursery. Grow Me Instead and Grow Local are internet-based and print guides to plant choice designed to promote local plants. Bushcare is a 
council initiative that runs volunteer groups who remove invasive plants and restore bushland in their local area.

Surveys and follow-up letters were delivered to 2000 households from a population of approximately 7500 eligible households identified from City Council “Natural Area” maps. The Index of Relative Socio-Economic Advantage and Disadvantage (IRSAD) was used to stratify the Wollongong suburbs. In Australia, each suburb has an IRSAD value according to its socio-economic status, and been ranked into ten categories from one (most disadvantaged) to ten (most advantaged) (Pink 2011). Among Wollongong suburbs, we randomly chose several suburbs from each of the ten ranks to obtain responses across the ranks of socio-economic status. Within the chosen suburbs from each rank, we delivered 200 questionnaires. Finally, 382 questionnaires were sent back (response rate $=19.1 \%$ ). While the proportion of male and female respondents matched those proportions in Wollongong population, our respondents (median 55 years) tended to be older than the Wollongong population (median 38 years), more highly educated (43.2\% had Bachelor degrees compared to $19.3 \%$ of Wollongong population), and more likely to not be employed (59.8\% of respondents were employed compared to 93\% of Wollongong population over 15 years) (Australian Bureau of Statistics 2011). Some other studies about gardening (Head and Muir 2004; Kiesling and Manning 2010) showed that respondents generally were older and more likely to be female than the general population. This study shows the same trend in age with previous studies.

The questionnaire was designed to measure the selected variables, and was piloted with ten Wollongong residents, who were volunteers of a local educational institute, and were 
selected for living adjacent to bushland. The descriptive information and alpha values of all variables are presented in table 1.

Obtaining garden plants was measured by asking: "how often do you buy or obtain garden plants”, scored from never (0), less than once a year (1), at least once a year (2), at least once every three months (3), at least once a month (4), to at least once a week (5). This variable was used to indicate the frequency of making plant choice, and only involved in correlation analysis.

Plant choice was measured by "please indicate what kind of garden plants you have obtained in the last 12 months”. Response options include: unsure (0), only non-native plants (1), mainly non-native plants (2), mainly native plants (3), and only native plants (4). The choice unsure (9.1\%) was treated as missing value. In the pilot study, we found gardeners can be trusted to know what a native species is. In another study covering our study area, Head and Muir (2004) found local gardens usually contained a mix of native and non-native plants. While it is not always obvious which plants are native, in Australia, the choice between native and non-native plants is a key axis by which preferences are expressed in gardening.

Weeding INR [in the neighboring reserve(s)] and bush restoration INR were measured by “please indicate how often you did the following activities in the neighboring reserve(s) in the last spring and summer”, scored from never (0), less than every three months (1), at least every three months (2), at least once a month (3), at least every fortnight (4), to at least once a week (5). The mean of each respondent's scores of these two behaviors was used as bush-friendly behavior. Weeding and bush restoration are frequently organized by Bushcare groups. Their importance for weed management has been reported (Rose 1997). Plant choice 
and bush friendly behavior were dependent variables in the analyses with all variables in the following as independent. In path analysis, missing values were handled by hot deck imputation with gender, education and age serving as deck variables.

All items of following variables were coded on a five-point scale. The mean of the scores for the items under each variable constituted the score for each variable. The items of attitude, subjective norm, self-control, and time pressure were scored from strongly disagree (1) to strongly agree (5) with reversed items coded in reverse.

Four items measured attitude: "I find the idea of planting native plants disagreeable" (reversed), “I find the idea of planting native plants unpleasant” (reversed), “My feelings towards planting native plants are favorable”, "I find the idea of planting native plants pleasing”. This measure is based on Knussen and Yule's (2008) 6-item attitude scale, with two items discarded in the pre-test.

Two items measured subjective norm: "I think mainly planting native plants is a common practice among my friends and relatives”, and “a common practice among Australians” (Ajzen 1991).

Eight items measured self-control: a. "Before I decide to obtain garden plants, I will try to find out some information about them to justify my purchase"; b. "Before I decide to obtain garden plants, I will think about the future impact of planting them in my garden”; c. "When I decide to obtain a garden plant, I should be very clear on which plants I should not choose (e.g. plants which may not fit my garden)”; d. "When I see a garden plant I really like, I try to obtain it immediately without thinking about any negative aspects related to it” (reversed); e. "It is hard for me to resist obtaining the plant I really like” (reversed); f. 
“Choosing garden plants is a trivial matter, I do not usually pay much attention to it” (reversed); g. "Even if planting a certain plant in my garden is going to have some negative consequences, it may not be a big deal, so I will not care too much" (reversed); h. "Even if a garden plant is very attractive to me, I will not obtain it if I know the consequences may be bad (such as it becoming a weed in the neighboring environment)”. The design of these items was based on Tangney et al. (2004) and Whiteside and Lynam (2001).

To measure time pressure, Roxburgh’s (2002) 9-item time pressure scale was pre-tested, and two items were discarded. The remaining seven items were employed: "I never seem to have enough time to get everything done”, "I feel rushed or pressed for time”, "I am often in a hurry”, "I have enough time for myself” (reversed), "I feel that too much is expected of me”, “I worry about how I am using my time”, and “I am always running out of time”.

Three items measured perceived harm: "to what extent you think non-native plants in general are harmful to bushland near to your home”, “Australia’s natural environment”, and “Australian agriculture”, all scored from not harmful (1) to extremely harmful (5) (Oreg and Katz-Gerro 2006).

Intention to increase and intention to remove were both measured by one item: "to what extent do you have any intention to increase the extent to which your garden is made of native plants”, and “remove the non-native plants found in the neighboring reserve(s)”, scored from no intention (1) to firm intention (5). Courneya (1994) argued one item should be enough to measure intention, because it is a straightforward construct. 
Four items measured knowledge of initiatives: "please indicate your level of knowledge of Greenplan”, “Bushcare”, “Grow Local” and “Grow Me Instead” (Mobley et al. 2010), all scored from no knowledge (1) to a lot of knowledge (5).

Finally, people were asked to describe the boundary between their property and the neighboring reserve(s) (boundary type), and indicate what is their most important source of new garden plants (plant source).

\section{Analysis}

The scale reliability of self-control was examined by one-dimension categorical principal components analysis (CATPCA) and confirmatory factor analysis (CFA). Descriptive and correlation analyses were conducted to explore relationships among variables. Ordinal regression was used to evaluate each variable's direct effect on plant choice (considering that plant choice was measured on a four-point scale and should be treated as an ordinal variable), with all variables that had a significant WALD test statistic being involved into the final model, and three independent variables were involved (intention to increase, attitude, plant source). A hierarchical multiple linear regression model was built to identify each factor's direct effect on bush-friendly behavior (considering the continuous nature of variable bush-friendly behavior), and four independent variables were involved (boundary type, intention to remove, knowledge of initiatives, time pressure). This regression model was also used to determine whether time pressure moderated the relationship between intention to remove and bush-friendly behavior. 
We used path analysis (two path models) to examine each continuous variable’s indirect effect on plant choice and bush-friendly behavior, and the applicability of the TRA with additional variables. Both models had attitude, perceived harm and knowledge of initiatives as independent variables. Intention to increase and self-control were specifically involved in the model for plant choice. Intention to remove was specifically involved in the bush-friendly behavior model.

\section{Results}

For self-control, the Cronbach's alpha in one-dimension CATPCA was .788, with $40.27 \%$ of the variance explained. Most of the 8 items correlated more than 0.3 with at least one other item, and component loadings for items a-h were respectively .671, .746, .645, .664, .431, .643, .679, and .546 (variable principal normalization was used). In the CFA model, we used Bollen-Stine $p$-value to evaluate the overall model fit because of non-normality (Mardia’s multivariate kurtosis was 24.373, and the critical ratio was 18.830$)$. The $p$-value was .315, and the mean value of chi square was 18.181, indicating good model fit.

Table 1 shows the correlation coefficients of variables. Intention to increase and intention to remove respectively have a strong correlation with plant choice and bush-friendly behavior. Attitude and subjective norm are correlated with plant choice, but have nearly no correlation with bush-friendly behavior. Positive correlations exist between knowledge of initiatives and plant choice or bush-friendly behavior. Bush-friendly behavior is negatively correlated with time pressure. 


\section{Regression analysis}

In ordinal regression, two models (table 2) were built (base and final model). The base model included one independent variable (intention to increase, considering its potential influence suggested by the TPB/TRA). In the base model (Nagelkerke pseudo $R^{2}=27.8 \%$ ), the odds of having a higher plant choice (choosing a higher proportion of native plants) increased by 2.25 times for each unit increase in intention to increase. In the final model (Nagelkerke pseudo $R^{2}$ $=31.4 \%$ ), respondents with one unit higher in intention to increase were 1.93 times more likely to have a higher plant choice. A one-unit increase in attitude led to an increase in odds of having a higher plant choice by 1.55 times. For plant source, respondents who chose botanic garden/Greenplan were 2.8 times more likely to have a higher plant choice than respondents who nominated nurseries. Respondents who chose other sources did not have a significant difference in plant choice from respondents who chose nurseries.

In linear regression (table 3), situational variables (Mobley et al. 2010), and intention to remove were entered at the first two steps considering their potential effects. Time pressure was entered at the last step to examine its effect after other variables were controlled for. In each step, insignificant variables were removed. Four variables, including one nominal variable (boundary type), were involved in the model $\left[F(11,272)=15.373, p<.001 ; R^{2}=\right.$ .383]. The Variance Inflation Factors of all independent variables ranged from 1.061 to 2.814 (within the acceptable limit of 10). For boundary type, “no fence or a boundary formed by plants" had a significant association with the outcome $(\beta=.179, p<.05)$. Intention to remove $(\beta=.42, p<.001)$ and knowledge of initiatives $(\beta=.198, p<.001)$ were the most significant variables. When time pressure was entered, it remained significant $\left(\Delta R^{2}=.009 ; \beta=-.099, p<\right.$ 
$\left..05 ; F_{\text {change }}=4.113, p<.05\right)$ after three variables were controlled for.

To determine whether time pressure moderated the intention-behavior relationship, an interaction term was calculated by multiplying intention to remove by time pressure. The interaction variable was added to the previous regression model following time pressure. Its effect on bush-friendly behavior was significant: $\Delta R^{2}=.012 ; \beta=-.391, p<.05 ; F_{\text {change }}$ (12, $271)=5.188, p<.05$. It indicated when respondents perceived more time pressure, the effect of intention to remove on bush-friendly behavior became weaker.

\section{Path analysis}

In path analyses, final models were determined according to best-fitting models generated by model building processes. We also kept the relationship between subjective norm and intentions according to the TRA. The overall fit for the model of plant choice (figure 1a) was $\operatorname{good}\left[\chi^{2}=13.01, d f=8, p=.11\right.$; Adjusted Goodness of Fit Index $($ AGFI $)=.97$; Comparative Fit Index $(\mathrm{CFI})=.98$; Root Mean Square Error of Approximation $($ RMSEA $)=.041]$. All of the given relationships were significant except for the relationship between subjective norm and intention to increase $(p=.57)$. Intention to increase was the most powerful explanatory variable of plant choice. Intention was further predicted by five variables, and attitude was the strongest. Additionally, subjective norm directly influences plant choice.

The overall fit for the bush-friendly behavior model (figure 1b) was also good $\left(\chi^{2}=\right.$ 8.47, $d f=5, p=.13 ;$ AGFI $=.97 ; \mathrm{CFI}=.98 ;$ RMSEA $=.054)$. All of the given relationships were significant except for subjective norm to intention to remove $(p=.80)$. Bush-friendly behavior was directly related with intention to remove and knowledge of initiatives. The 
intention-behavior relationship turned out to be the strongest relationship. Intention to remove was further explained by four variables, and knowledge of initiatives was the strongest.

\section{Discussion}

This study adds explanation to garden-related environmental behaviors which have not been widely studied compared to other environmental behaviors, and adds support to most of the TPB/TRA variables. To extend the TPB/TRA, we evaluated self-control, time pressure and knowledge of initiatives. Self-control influences intention to increase the proportion of native garden plants, and time pressure influences bush-friendly behavior. It supports the suggested revisions of the TPB/TRA by searching for additional predictors.

For both plant choice and bush-friendly behavior, intention is the most powerful explanatory variable, which concurs with other studies (Barr 2008) and the TPB/TRA. For both intention to increase and intention to remove, subjective norm is not a significant predictor. The weak effect of subjective norms has been reported elsewhere as a shortcoming of the TPB/TRA (Chao 2012). Here, subjective norm is significantly related to plant choice in path analysis, but is insignificant in regression analysis when plant source is introduced as an explanatory variable, showing respondents' subjective norm is influenced by what source they choose to obtain plants from, or the effect of subjective norms is subject to other variables.

The two intentions are significantly related to attitude and perceived harm, which is in line with the TPB/TRA, suggesting that, in order to increase people's environmental 
intentions, it is important to encourage them to foster a positive attitude towards planting native plants, and engage them to foster knowledge about the harm of invasive plants.

The two intentions and bush-friendly behavior are explained by knowledge of initiatives. Because the initiatives provide people with affordable local plants, it is reasonable that knowledge of initiatives leads to a higher intention to increase. Moreover, Dolnicar et al. (2012) reported that those performing conservation behavior make significantly more efforts to search for information about relevant issues. Those frequently performing bush-friendly behavior may also actively search for information about weed issues, reflected as a higher knowledge of initiatives. To enhance people’s knowledge of initiatives, authorities should make the initiatives more accessible to local residents as we found the initiatives are not well known (the mean of knowledge of initiatives is 1.95).

Intention to increase is negatively related to self-control, implying that obtaining exotic garden plants can be related to self-control failure or impulse evoked by the attractive appearance of exotic plants (Ditto et al. 2006). A high percentage of impulse buying in the market of garden plants has been reported (HRDC 1991). To reduce impulse buying of exotic plants, strategies can focus on how to cancel out the effect of exotic plants' attractive appearance. Environmental messages can be presented in the form of posters or multimedia that vividly reveal the harm of invasive plants and may inspire negative feelings towards them. Alternatively, weed-control initiatives can produce material that highlights how native, or non-invasive plants, can provide the aesthetic characteristics that gardeners want (Thøgersen 2005). 
Besides intention, plant choice is explained by attitude and plant source in ordinal regression. The significance of attitude underscores the importance of fostering a positive attitude regarding native plants among gardeners. For plant source, respondents who mainly obtain garden plants from nurseries do not obtain a higher proportion of native plants than others. Moss and Walmsley (2005) reported that nurseries frequently stock potential invasive species to generate business. To shift the fashion towards native or non-invasive plants, education alone will not be enough. It requires a broader cultural change that favors nativeness or non-invasive characteristics, augmented by stricter regulation on the sale of potentially invasive plants.

To this point, our recommendations focus on two issues. First, the presentation of environmental information and, second, the outlets where people obtain plants. Properly presented environmental information is important, because it can stimulate positive attitudes towards natives or non-invasives, negative attitude towards invasives, and reduced impulse buying of exotic plants. Environmental information can be presented through initiatives or at places where gardeners obtain plants. But the effectiveness of environmental information depends on whether plant retailers are willing to inform people the harm of invasive plants. These plant outlets influence people’s propensity towards buying certain group of plants and should be strictly regulated or otherwise engaged with.

For bush-friendly behavior, there are four significant explanatory variables and one interaction term. Intention to remove and knowledge of initiatives have been discussed previously. Having no fence or a boundary formed by plants is significantly related to 
bush-friendly behavior. Head and Muir (2006) reported gardeners who were more likely to grow native plants were more likely to keep their gardens open to bushland.

Bush-friendly behavior is negatively related to time pressure. When time pressure becomes higher, the intention-behavior relationship becomes weaker, indicating that time pressure contributes to a "intention-behavior gap”, which concurs with previous studies (Thøgersen 2005). But time pressure is not significantly correlated with plant choice or obtaining garden plants that is performed far more frequently than bush-friendly behavior. Prillwitz and Barr (2011) reported that convenient behavioral changes are directly influenced by attitudes, and are easier to trigger than inconvenient behavior. In this study, plant choice is significantly correlated with attitude, while bush-friendly behavior is not. It makes sense that inconvenient behavior (bush-friendly behavior) is more influenced by time pressure, and convenient behavior (plant choice or obtaining garden plants) is more frequent or easier to trigger. For weed-control initiatives, encouraging gardeners to purchase native plants tends to be more effective than encouraging bush-friendly behavior.

The main shortcoming of this study is that we used self-reported past behavior as the dependent variable. Although past behavior has been widely used as dependent variable in behavior research (Oreg and Katz-Gerro 2006), the significant relationships in the analyses cannot reflect true causality among variables.

In summary, the TRA with extra variables explained less variance in plant choice or bush-friendly behavior than the regression models partly due to the extra nominal variables in the regression analyses. It suggests that the TRA sets a base for explaining behavior, but different behaviors have different characteristics which may only be explained by specific 
factors connected with them. Plant choice (choosing native plants) belongs to buying behavior, so it is related to plant source and receives an indirect effect from self-control (resistance to impulse buying). Bush-friendly behavior is an inconvenient or time-consuming behavior, so time pressure moderated its relationship with intention to remove. Self-control and time pressure have been reported to influence general environmental behavior (Thøgersen 2005; Kennedy et al. 2009), but it is seldom mentioned that they probably only influence behavior from limited domains (self-control probably only influences resistance to impulsive behavior; time pressure probably only influences inconvenient behavior). It is accepted that the proportion of variance in intention and behavior unexplained by the TPB/TRA is partly due to the lack of certain variables (Payne et al. 2004). For future research, it will be valuable to categorize environmental behaviors, and search explanatory variables or models according to each category.

\section{Conclusion}

The kind of plants local residents grow and how they behave in nearby reserve(s) exert a far-reaching influence on the bushland. This study provides an exploratory case for garden-related environmental behaviors. The practical implication lies in the recommendations for weed management. Firstly, retail nurseries influence consumers' plant choice, and their role on ongoing distribution of potentially invasive plants can once again be highlighted. The significance of perceived harm and attitude suggests it is important to use environmental information as an agent to cultivate residents' environmentally responsible attitude as an impetus for pro-environmental behavior. The positive role of weed-control 
initiatives is revealed. It is valuable for relevant authorities to make such initiatives more accessible or expanded. The initiatives can provide local residents with practical suggestions about weed removal and bush restoration to make them less time-consuming. It is also important to highlight how native or non-invasive plants can provide the aesthetic characteristics that gardeners want. Future research can help to design and apply intervention strategies based on the identified factors to change the environmentally detrimental behavior of certain local residents. 


\section{References}

Ajzen, I. 1991. The theory of planned behavior. Organizational Behavior and Human Decision Processes 50(2):179-211.

Australian Bureau of Statistics. 2011. 2011 Census QuickStats. Http://www.censusdata.abs.gov.au/census_services/getproduct/census/2011/quickstat/L GA18450?opendocument\&navpos=220 (accessed 8 June 2014).

Barr, S. 2008. Environment and society: Sustainability, policy and citizen. Aldershot: Ashgate Publishing Limited.

Blood, K., and D. Slattery. 1996. “I’ve got angled onion in my garden and I reckon it’s OK!” environmental weeds and community education. In Eleventh Australian Weeds Conference Proceedings, Victoria.

Chao, Y. 2012. Predicting people’s environmental behaviour: Theory of planned behaviour and model of responsible environmental behaviour. Environmental Education Research 18(4):437-461.

Collette, M., G. Godin, R. Bradet, and N.J. Gionet. 1994. Active living in communities: Understanding the intention to take up physical activity as an everyday way of life. Canadian Journal of Public Health 85:418-421.

Courneya, K.S. 1994. Predicting repeated behavior from intention: The issue of scale correspondence. Journal of Applied Social Psychology 24(7):580-594.

Davison, A., and B. Ridder. 2006. Turbulent times for urban nature: Conserving and re-inventing nature in Australian cities. Australian Zoologist 33(3):306-314. 
Dignam, M., and associates. 2003. Nursery and garden industry consumer research. Sydney: Horticulture Australia Ltd.

Ditto, P.H., D.A. Pizarro, E.B. Epstein, J.A. Jacobson, and T.K. Macdonald. 2006. Visceral influences on risk-taking behavior. J. Behav. Dec. Making 19(2):99-113.

Dolnicar, S., A. Hurlimann, and B. Grün. 2012. Water conservation behavior in Australia. Journal of Environmental Management 105(14):44-52.

Fishbein, M., and I. Ajzen. 1975. Belief, attitude, intention, and behavior: An introduction to theory and research. Reading, MA: Addison-Wesley.

Garden, J.G., C.A. McAlpine, and H.P. Possingham. 2010. Multi-scaled habitat considerations for conserving urban biodiversity: Native reptiles and small mammals in Brisbane, Australia. Landscape Ecol 25:1013-1028.

Groves, R.H., R. Boden, and W.M. Lonsdale. 2005. Jumping the garden fence: Invasive garden plants in Australia and their environmental and agricultural impacts. CSIRO report prepared for WWF-Australia. Sydney: WWF-Australia.

Gunthorpe, W., and K. Lyons. 2004. A predictive model of chronic time pressure in the Australian population: Implications for leisure research. Leisure Sciences 26(2):201-213.

Head, L., and P. Muir. 2004. Nativeness, invasiveness, and nation in Australian plants. Geographical Review 94(2):199-217.

Head, L., and P. Muir. 2006. Edges of connection: Reconceptualising the human role in urban biogeography. Australian Geographer 37(1):87-101.

Hjorthol, R. 2001. Gendered aspects of time related to everyday journeys. Acta Sociologica 44(1):37-49. 
Hobbs, R.J., S. Arico, J. Aronson, J.S. Baron, P. Bridgewater, V.A. Cramer, P.R. Epstein, et al. 2006. Novel ecosystems: theoretical and management aspects of the new ecological world order. Global Ecology and Biogeography 15(1):1-7.

HRDC (Horticultural Research and Development Corporation). 1991. National consumer and retailer study of nursery industry opportunities 1991: A marketing research report. Canberra: Horticultural Research and Development Corporation.

Kennedy, E.H., T.M. Beckley, B.L. McFarlane, and S. Nadeau. 2009. Why we don’t “walk the talk”: Understanding the environmental values/behaviour gap in Canada. Human Ecology Review 16(2):151-160.

Kiesling, F.M., and C.M. Manning. 2010. How green is your thumb? Environmental gardening identity and ecological gardening practices. Journal of Environmental Psychology 30:315-327.

Knussen, C., and F. Yule. 2008. "I'm not in the habit of recycling": the role of habitual behavior in the disposal of household waste. Environment and Behavior 40:683-702.

Lassen, C. 2010. Environmentalist in business class: An analysis of air travel and environmental attitude. Transport Reviews 30(6):733-751.

Lautenschlager, L., and C. Smith. 2007. Understanding gardening and dietary habits among youth garden program participants using the theory of planned behavior. Appetite 49(1):122-130.

Lorenzoni, I., S. Nicholson-Cole, and L. Whitmarsh. 2007. Barriers perceived to engaging with climate change among the UK public and their policy implications. Global Environmental Change 17(3):445-459. 
Loewenstein, G. 1996. Out of control: Visceral influences on behavior. Organizational Behavior and Human Decision Processes 65(3):272-292.

Loewenstein, G., and T. O’Donoghue. 2004. Animal spirits: Affective and deliberative processes in economic behavior. Ithaca, NY: Cornell University, Center for Analytic Economics.

Miller, J.R., and R.J. Hobbs. 2002. Conservation where people live and work. Conservation Biology 16(2):330-337.

Mobley, C., W.M. Vagias, and S.L. DeWard. 2010. Exploring additional determinants of environmentally responsible behavior: The influence of environmental literature and environmental attitudes. Environment and Behavior 42(4):420-447.

Moss, W., and R. Walmsley. 2005. Controlling the sale of invasive garden plants: Why voluntary measures alone fail. WWF-Australia Discussion Paper. Sydney: WWF-Australia.

Oreg, S., and T. Katz-Gerro. 2006. Predicting proenvironmental behavior cross-nationally: Values, the theory of planned behavior, and value-belief-norm theory. Environment and Behavior 38(4):462-483.

Payne, N., F. Jones, and P.R. Harris. 2004. The role of perceived need within the theory of planned behaviour: A comparison of exercise and healthy eating. British Journal of Health Psychology 9:489-504.

Pink, B. 2011. Socio-economic indexes for areas (SEIFA). ACT: Australian Bureau of Statistics. 
Power, E.R. 2005. Human-nature relations in suburban gardens. Australian Geographer 36(1):39-53.

Prillwitz, J., and S. Barr. 2011. Moving towards sustainability? Mobility styles, attitudes and individual travel behaviour. Journal of Transport Geography 19(6):1590-1600.

Rose, S. 1997. Integrating management of Pittosporum undulatum with other environmental weeds in Sydney's urban bushland. Pacific Conservation Biology 3(4):350-365.

Roxburgh, S. 2002. Racing through life: The distribution of time pressures by roles and role resources among full-time workers. Journal of Family and Economic Issues 23(2):121-145.

Sullivan, J.J., S.M. Timmins, and P.A. Williams. 2005. Movement of exotic plants into coastal native forests from gardens in northern New Zealand. New Zealand Journal of Ecology 29(1):1-10.

Sutton, S. 1998. Predicting and explaining intentions and behavior: How well are we doing? Journal of Applied Social Psychology 28(15):1317-1338.

Tangney, J.P., R.F. Baumeister, and A.L. Boone. 2004. High self-control predicts good adjustment, less pathology, better grades, and interpersonal success. Journal of personality 72(2):271-324.

Thøgersen, J. 2005. How may consumer policy empower consumers for sustainable lifestyles? Journal of Consumer Policy 28(2):143-178.

Turner, P.J., and P.O. Downey. 2010. Ensuring invasive alien plant management delivers biodiversity conservation: Insights from an assessment of Lantana camara in Australia. Plant Protection Quarterly 25(3):102-110. 
Tzavaras, M., I. Tzimitra-Kalogianni, and M. Bourlakis. 2010. Consumer behaviour in the Greek floral market: Comparative insights for the food industry. British Food Journal 112(4):403-415.

Verplanken, B., and A. Sato. 2011. The psychology of impulse buying: An integrative self-regulation approach. J Consum Policy 34(2):197-210.

Vohs, K.D., and R.J. Faber. 2007. Spent resources: Self-regulatory resource availability affects impulse buying. Journal of Consumer Research 33(4):537-547.

Whiteside, S.P., and D.R. Lynam. 2001. The five factor model and impulsivity: Using a structural model of personality to understand impulsivity. Personality and Individual Differences 30(4):669-689.

Zagorski, T., J.B. Kirkpatrick, and E. Stratford. 2004. Gardens and the bush: Gardeners' attitudes, garden types and invasives. Australian Geographical Studies 42:207-220. 


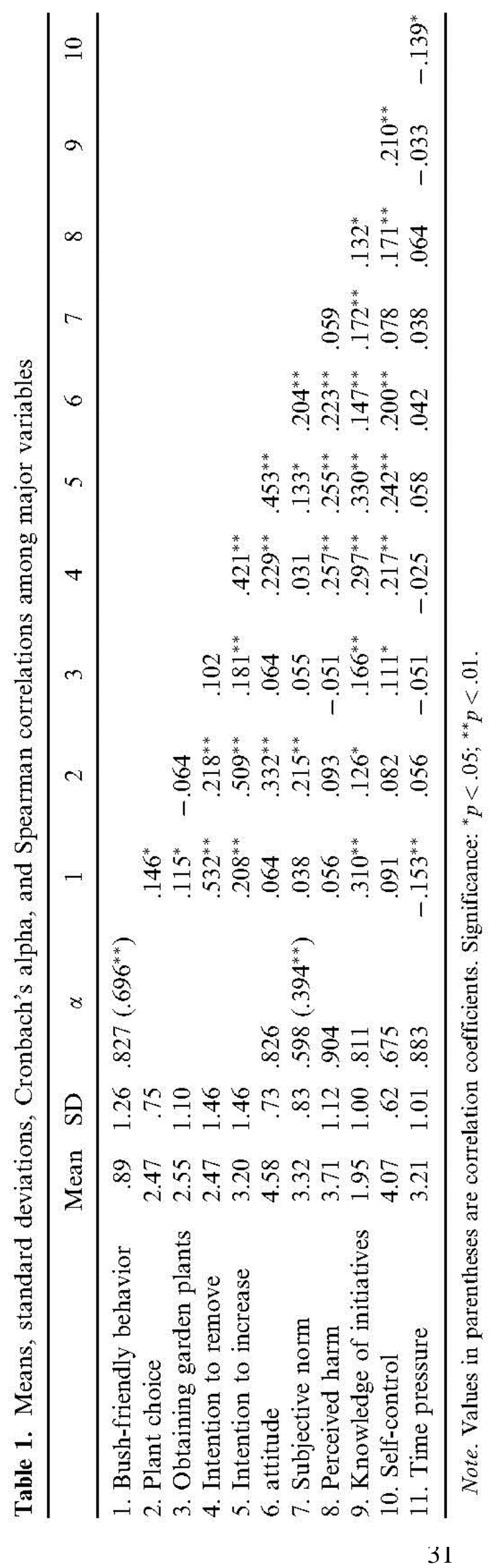


Table 2. Ordinal regression model for plant choice

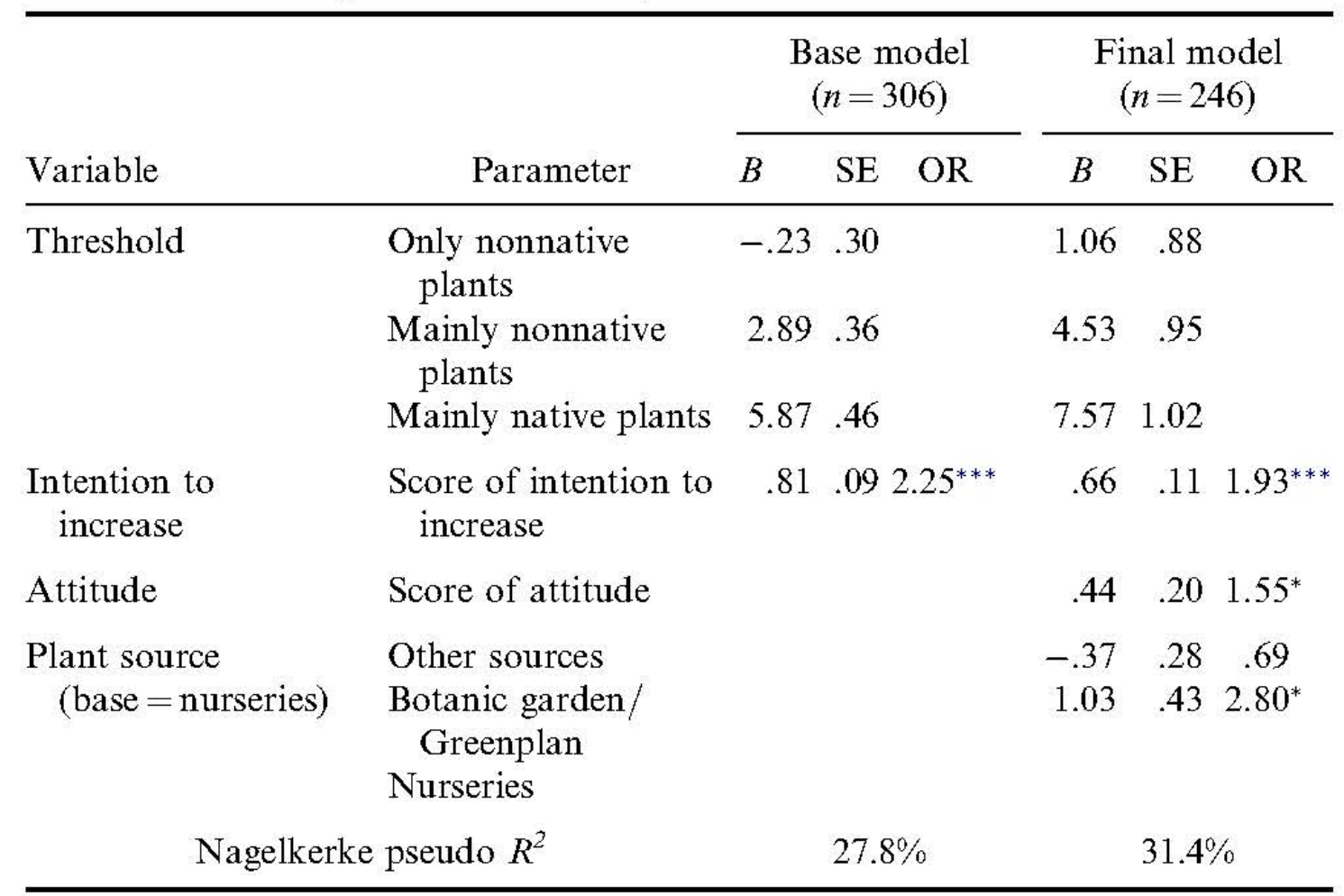

Note. For intention to increase and attitude, base $=$ the highest value. Significance: ${ }^{*} p<.05$; ${ }^{* * *} p<.001$.

Table 3. Hierarchical multiple linear regression model for bush-friendly behavior

\begin{tabular}{|c|c|c|c|c|c|c|}
\hline Step & & Variable & $R^{2}$ & $\Delta R^{2}$ & $F_{\text {change }}$ & Final $\beta$ \\
\hline \multirow[t]{9}{*}{1} & \multirow{9}{*}{$\begin{array}{l}\text { Boundary } \\
\text { type: }\end{array}$} & Other & \multirow[t]{9}{*}{.116} & \multirow[t]{9}{*}{.116} & \multirow[t]{9}{*}{$4.496^{* * *}$} & -.003 \\
\hline & & High solid fence no gate (reference) & & & & \\
\hline & & High solid fence with gate & & & & .124 \\
\hline & & Short solid fence no gate & & & & -.064 \\
\hline & & Short solid fence with gate & & & & .117 \\
\hline & & Look-through fence no gate & & & & -.007 \\
\hline & & Look-through fence with gate & & & & .148 \\
\hline & & Road or track & & & & -.024 \\
\hline & & $\begin{array}{l}\text { No fence or a boundary formed by } \\
\text { plants }\end{array}$ & & & & $.179^{*}$ \\
\hline 2 & \multicolumn{2}{|c|}{ Intention to remove } & .335 & .219 & $90.216^{* * *}$ & $.429^{* * *}$ \\
\hline 3 & \multicolumn{2}{|c|}{ Knowledge of initiatives } & .374 & .039 & $17.149^{* * *}$ & $.173^{* * *}$ \\
\hline 4 & \multicolumn{2}{|c|}{ Time pressure } & .383 & .009 & $4.113^{*}$ & $-.119^{*}$ \\
\hline
\end{tabular}

Note. $F(11,272)=15.373, p<.001$. Significance: ${ }^{*} p<.05{ }^{* * *} p<.001$. 

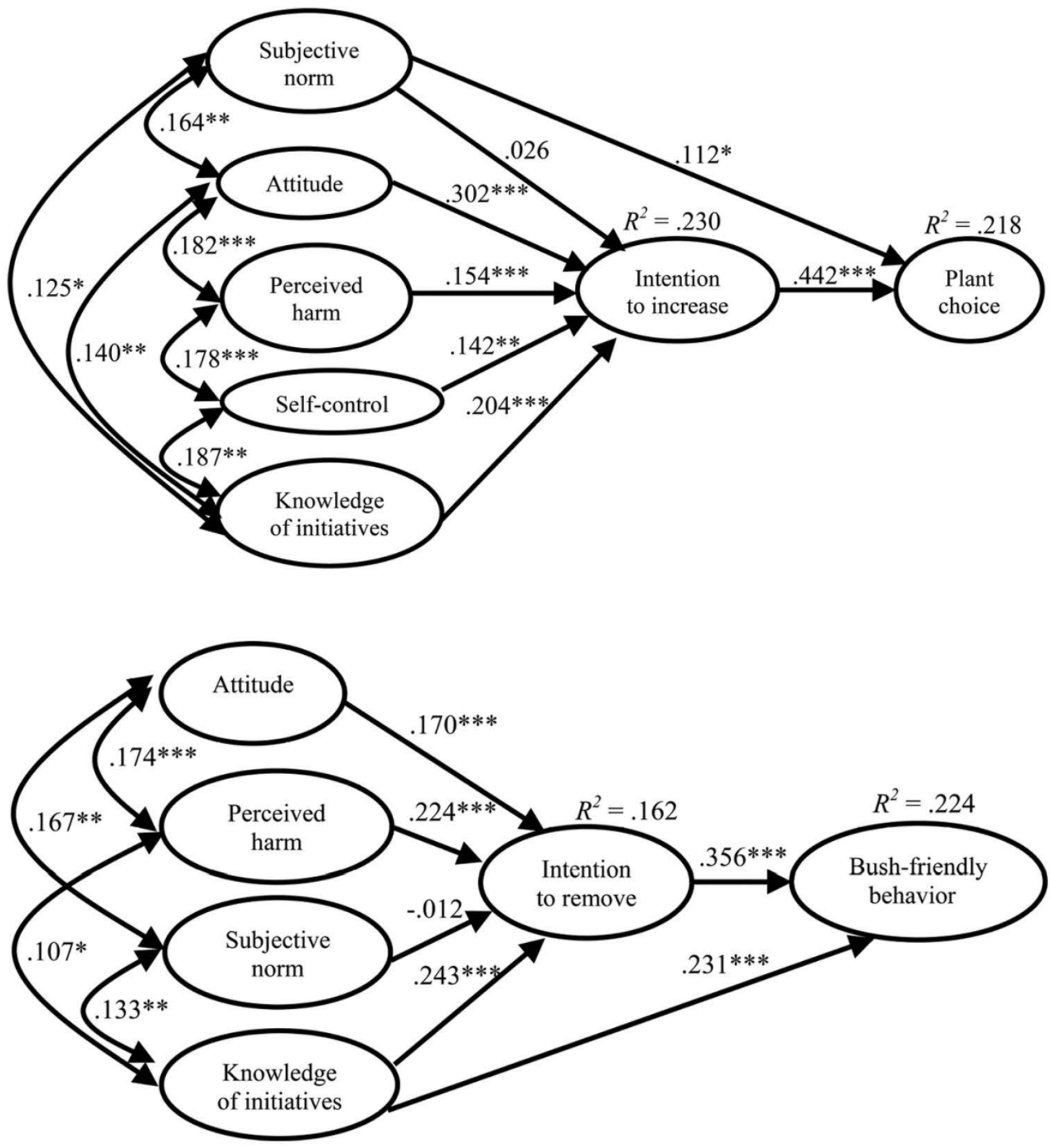

Figure 1. (a) Path model results for plant choice $(n=382)$. Single-headed arrows $=$ standardized path-coefficients; double-headed arrows $=$ correlations; $R^{2}=$ explained variance. Significance: ${ }^{*} p<.05 ;{ }^{* *} p<.01 ;{ }^{* * *} p<.001$. (b) Path model results for bush-friendly behavior $(n=382)$. Single-headed arrows $=$ standardized path-coefficients; double-headed arrows $=$ correlations; $R^{2}=$ explained variance. Significance: ${ }^{*} p<.05 ;{ }^{* *} p<.01 ;{ }^{* * *} p<.001$. 